\title{
Role of Periodontal Therapy in Rapid Tooth Movement
}

\author{
Pan Chern Hwei ${ }^{1}$, Dr. Julie Toby Thomas ${ }^{2}$ \\ ${ }^{I}$ Department of Periodontics, Saveetha Dental College and Hospital, India \\ ${ }^{21}$ Department of Periodontics, Saveetha Dental College and Hospital, India
}

\begin{abstract}
Periodontally accelerated osteogenic orthodontics (PAOO) or Wilckodontics is a clinical procedure that combines selective alveolar corticotomy, particulate bone grafting and the application of orthodontic forces. The most important factor in the success of PAOO is proper case selection and careful surgical and orthodontic treatment. An increasing amount of orthodontic patients seeking orthodontic treatment, make them prone to periodontal complications since their teeth are confined to the nonflexible alveolar bone. Interdisciplinary orthodontic treatment along with tissue engineering principles can create rapid orthodontic tooth movement as well as reducing side effects such as root resorption, relapse, inadequate basal bone and infection. Many of these challenging aspects facilitate the necessities of special concepts where PAOO technique opened doors and offered solutions to many limitation in orthodontic treatment. The aim of this article was to provide an overview of the literature including the historical background, indications, contraindication, the biological aspect of PAOO and the surgical technique and modifications of the same.
\end{abstract}

Keywords: Osteogenic, Periodontally accelerated osteogenic orthodontics, Rapid orthodontics, Regional acceleratory phenomenon and Wilckodontics.

\section{INTRODUCTION}

World Health Organization defined malocclusion as an anomaly which causes disfigurement or which impedes function, and requiring treatment "if the disfigurement or functional defect was likely to be an obstacle to the patient's physical or emotional well-being". Many surveys have been carried out in different part of the world to estimate the prevalence of malocclusion and the need for orthodontic treatment. Sandhu et al ${ }^{1}$ stated that the prevalence of class II malocclusion is lower in the Indian population compared to the Caucasian population. The frequency of class I malocclusion is greatest followed by class II and class III. In recent years, there is an increasing amount of adult patients seeking orthodontic treatment to improve their esthetics and selfesteem $^{2}$. However, orthodontic treatment is difficult in adults compared to adolescents due to the increased chance of hyalinization of bone, the increased risk for periodontal problems and the reduced tissue turnover in adults $^{3}$. Due to these reasons, an interdisciplinary orthodontic tooth movement is necessary to provide shorter treatment periods and to reduce side effects of orthodontic tooth movement. Kole et $\mathrm{al}^{4}$ acknowledged that without the help of surgical interventions, treatment is seldom possible in patients older than 16 years. Wilcko and Ferguson et al introduced a new technique which combines selective decortication facilitated orthodontic technique and alveolar augmentation ${ }^{5,6}$. This technique is known as periodontally accelerated osteogenic orthodontics (PAOO) .This technique allows teeth to be moved 2-3 times further in $1 / 3^{\text {rd }}$ to $1 / 4^{\text {th }}$ the time required for traditional orthodontic treatment ${ }^{5}$.

The aim of this article was to provide an overview of the literature including the historical background, indications, contraindication, the biological aspect of PAOO and the surgical technique and modifications of the same.

\section{Introduction}

World Health Organization defined malocclusion as an anomaly which causes disfigurement or which impedes function, and requiring treatment "if the disfigurement or functional defect was likely to be an obstacle to the patient's physical or emotional well-being". Many surveys have been carried out in different part of the world to estimate the prevalence of malocclusion and the need for orthodontic treatment. Sandhu et al ${ }^{1}$ stated that the prevalence of class II malocclusion is lower in the Indian population compared to the Caucasian population. The frequency of class I malocclusion is greatest followed by class II and class III. In recent years, there is an increasing amount of adult patients seeking orthodontic treatment to improve their esthetics and selfesteem $^{2}$. However, orthodontic treatment is difficult in adults compared to adolescents due to the increased chance of hyalinization of bone, the increased risk for periodontal problems and the reduced tissue turnover in adults ${ }^{3}$. Due to these reasons, an interdisciplinary orthodontic tooth movement is necessary to provide shorter treatment periods and to reduce side effects of orthodontic tooth movement. Kole et $\mathrm{al}^{4}$ acknowledged that without the help of surgical interventions, treatment is seldom possible in patients older than 16 years. Wilcko and Ferguson et al introduced a new technique which combines selective decortication facilitated orthodontic 
technique and alveolar augmentation ${ }^{5,6}$. This technique is known as periodontally accelerated osteogenic orthodontics (PAOO).This technique allows teeth to be moved 2-3 times further in $1 / 3^{\text {rd }}$ to $1 / 4^{\text {th }}$ the time required for traditional orthodontic treatment ${ }^{5}$.

The aim of this article was to provide an overview of the literature including the historical background, indications, contraindication, the biological aspect of PAOO and the surgical technique and modifications of the same.

\section{Historical Background}

The first surgically assisted orthodontic tooth movement has been documented since the first century ${ }^{7}$. L.C. Bryan in 1893, first described corticotomy facilitated tooth movement. However in 1959, Heinrich Kole ${ }^{4}$ described a more morbid technique as a mean for rapid tooth movement which involves vertical inter-radicular corticotomy both facially and lingually and are joined with osteotomy cuts $10 \mathrm{~mm}$ supra-apically. According to his concept, teeth are moved due to the movement of bony blocks of bone with orthodontic forces. Due to the obstruction to the continuity of bone after corticotomy, the segments of bone in which teeth are embedded could be moved rapidly and independent of each other. Major active tooth movement can be accomplished in 6-12 weeks compared to average orthodontic treatment time for adults, ranging from 18.7 to 31 months ${ }^{8,9}$.

Duker et al conducted an experiment on beagle dogs in 1975 and demonstrated that rapid tooth movement could be achieved by orthodontic appliances after weakening the bone by corticotomy ${ }^{10}$. The rapid tooth movement does not affect the vitality of the teeth which have been moved. The health of the periodontium is also maintained by avoiding corticotomy of the marginal bone.

Recently in 2008, Wilcko et $\mathrm{al}^{5}$ introduced a new technique known as periodontally accelerated osteogenic orthodontics (PAOO) which is the combination of selective decortication-faciliated orthodontics technique and alveolar augmentation. This technique increases the net alveolar volume after orthodontic treatment by using bone grafts which consists of demineralized reduce the treatment time to $1 / 3$ rd the time of conventional orthodontic treatment.

Limitation of a conventional orthodontic management is that in most cases the patient requires extraction, may result in relapse without the use of retainers, may compromise the health of periodontium due to excessive force and require a longer period of time for the completion of the treatment especially in adults.

\section{Biology Underlying PAOO}

Rapid tooth movement was thought to be due to the movement of bony blocks of bone after decortication. This was reported by Heinrich Kole in $1959^{4}$. In 2001, Wilcko et $\mathrm{al}^{11}$ reported that rapid tooth movement was not the result of movement of bony blocks but is due to the demineralization and remineralization of the alveolar bone around the tooth by a normal healing process known as regional acceleratory phenomenon (RAP).

\subsection{Regional Acceleratory Phenomenon (RAP)}

Regional acceleratory phenomenon was developed by Frost and Jee in $1983^{12,13}$. The decortication of bone results in an increased turnover of alveolar spongiosa with areas of alveolar demineralization. This results in osteopenia, where its mineral content temporarily decreased which enables teeth to be moved more rapidly and further through the collagenous soft tissue matrix of the bone $e^{6,13,14}$. Following the completion of orthodontic treatment, remineralization takes place resulting in greater stability in the orthodontic treatment outcome.

\section{Indications}

a. Resolve crowding and shorten treatment time.

b. Accelerate canine retraction after premolar extraction

c. Enhance post orthodontic stability

d. Facilitate eruption of impacted teeth

e. Facilitate slow orthodontic expansion

f. Molar intrusion and open bite correction

\section{Contraindications}

a. Patients with severe active periodontal disease.

b. Patients with inadequately treated endodontic problems.

c. Patients on long term medications which will slow down bone metabolism, such as bisphosphanate and NSAIDs. NSAIDs lead to prostaglandin inhibition resulting in reduced osteoclastic activity thus disturbing bone remodeling.

d. Patients on long term steroid theraphy due to the presence of devitalized areas of bone. 
e. Patients with compromised width of the attached gingiva.

\section{Surgical Technique}

Proper patient selection is crucial for the success of the procedure. After the treatment plan has been discussed by the orthodontist and the periodontist, orthodontic brackets are placed and a light wire engaged a week before the surgical procedure ${ }^{15}$. Surgery can be carried out with or without sedation.

\subsection{Flap Design}

The objectives of flap design include to provide access to the alveolar bone to perform corticotomies, to provide coverage of the bone graft, to maintain the height and volume of the interdental tissues, and to enhance the esthetic appearance of the gingival form. After administration of local anesthesia, sulcular releasing incisions are made lingually and labially. Full-thickness flaps are carefully reflected labially and lingually in the coronal aspect of the flap with a split thickness flap reflected at the apices of the teeth to allow mobility of the flap to enable the flap to be sutured with minimal tension. Proper identification of the neurovascular structures is important to prevent damage to these structures. The flaps should be extended beyond the corticotomy sites mesially and distally to prevent vertical releasing incisions. The interdental papilla can be reflected with the flap or left in place 5 . However, the interdental papilla between the maxillary central incisors is preserved for esthetic purposes $^{6}$. After flap reflection, the area is thoroughly debrided and curettage done to remove any inflamed tissue, if present.

\subsection{Decortication}

Corticotomy is defined as a surgical procedure whereby only the cortical bone is cut, perforated or mechanically altered. Decortication should just be enough to initiate the RAP response and not to create bone segments ${ }^{16}$. Alveolar bone is activated with selective decortications performed lingually and labially using round burs with water irrigation. Corticotomies can also be achieved using piezoelectric knife ${ }^{17}$. Vertical corticotomy cuts are made just short of the alveolar crest between the roots of teeth. The corticotomy extends from a point $2-3 \mathrm{~mm}$ below the crest of the bone to a point $2 \mathrm{~mm}$ beyond the apices of the roots ${ }^{18}$. These cuts are connected by scalloped horizontal corticotomy cuts. Cortical perforations are made at selected areas to increase the blood supply to the graft material ${ }^{11}$.

\subsection{Particulate Grafting}

Bone graft materials are placed in decorticated areas. The most commonly used materials include deproteinized bovine bone, autogenous bone, decalcified freeze dried bone allograft, or a combination of these ${ }^{7,18}$. Wilcko et al introduced the use of mix of demineralized freeze-dried bone with bovine bone and clindamycin. The particulate bone graft can also be wet with plate-rich plasma to facilitate the placement of the graft and to increase the stability of the graft material ${ }^{15,18}$. The volume of particulate bone graft used is 0.25 $0.5 \mathrm{ml}$ per tooth. Excess amount of grafting material should be avoided to prevent interference with flap placement. Connective tissue graft or acellualar dermal matrix allograft ( Alloderm ) can be used to treat any recession cases.

\subsection{Closure}

The flaps are approximated with non resorbable interrupted sutures without excessive tension ${ }^{15,18}$. The specific suture used is based upon the thickness of the tissues ${ }^{18}$. The sutures are then left in place for a minimum of 2 weeks. For the epithelial attachment to re-establish itself, it is important to allow the sutures to be left for a sufficient period of time. Premature suture removal may lead to flap displacement, dark triangles, and gingival recession $^{15 \text { Error! Bookmark not defined. }}$. No packing is required.

\subsection{Orthodontic Treatment}

An immediate heavy orthodontic force should be applied on the teeth after flap repositioning. The initiation of orthodontic force should not be delayed more than 2 weeks as there is limited amount of time to accomplish accelerated tooth movement.

\subsection{Postsurgical Management}

Antibiotics, analgesics and antiseptic mouthwash should be prescribed to the patient. Long-term administration of nonsteroidal anti-inflammatory agents is discouraged as these may interfere with the regional acceleratory process ${ }^{18}$. To decrease any postoperative swelling, icepacks can be applied to the affected areas. The patient should be recalled to the periodontist every 3 months during orthodontic treatment for the assessment of periodontal health and oral hygiene status ${ }^{19}$. 


\section{Modifications In The Paoo Technique}

One of the drawbacks faced in the technique is the exposure of the root surfaces in some areas which can be due to the thin gingival biotype as well as thin cortical plate of bone. Hence, the usage of autogenous soft tissue graft such as connective tissue grafting which is still considered to be the gold standard among all other soft tissue grafting techniques can be included under the full thickness flap reflected. The graft can be harvested from the keratinized palatal side. Platelet rich plasma, platelet rich fibrin, and growth factors can also be included under the flap. The usage of platelet rich fibrin increases the stability of the graft ${ }^{18}$.

A study conducted by Sebaoun and coworkers on 36 healthy adult rats showed an increased turnover of alveolar spongiosa was seen after alveolar decortication which is likely to be the biology underlying rapid tooth movement after selective alveolar decortication ${ }^{13} .2$ cases of decrowding were reported by Wilcko and coworkers which demonstrated selective alveolar decortication, bone augmentation and orthodontic treatment. Rapid tooth movement was achieved in both cases without any significant apical root resorption. The authors suggested that the regional acceleratory phenomenon to be responsible for the tooth movement in these patients ${ }^{11}$. Recently, the application of piezoelectric decortication in 187 labial or lingual PAOO of maxillary and mandibular anterior teeth were evaluated. It was shown that there were significantly less alveolar fenestration and bony dehiscence after the ultrasonic decortications were performed ${ }^{20}$.

\section{Conclusion}

Periodontal accelerated osteogenic orthodontic has shown increased in alveolar bone thickness due to the inclusion of bone grafts, significantly reduces treatment time, better post orthodontic stability and incidence of root resorption is decreased compared to the conventional orthodontic treatment . However, long term treatment outcome of PAOO is still unavailable as the technique is still relatively new. A successful treatment therapy can be achieved by proper coordination between the orthodontist, periodontist and oral and maxillofacial surgeon and proper case selection.

\section{References}

[1]. S.S. Sandhu, .N Bansal and N. Sandhu . Incidence of malocclusion in India: A review. J Oral Health Comm Dent, 6(1), 2012, 2124.

[2]. T.G. Rappaport, M.H. Shalis and E. Gazit. Psychosocial reward of orthodontic treatment in adult patients. European Journal of Orthodontics, 32(4), 2010, 441-446.

[3]. M.M. Ong and H.L. Wang. Periodontic and orthodontic treatment in adults. Am J Orthod Dentofacial Orthop, 122(4), 2002, 420428.

[4]. H. Kole. Surgical operations on the Alveolar Ridge to Correct Occlusal Abnormalities. Oral Surg Oral Med Oral Path, 12(5), 1959, 515-529.

[5]. M.T. Wilcko, W.M. Wilcko, and N.F. Bissada. An evidence-based analysis of periodontally accelerated orthodontic and osteogenic techniques: a synthesis of scientific perspectives. Seminars in Orthodontics , 14(4), 2008, 305-316.

[6]. D.J. Ferguson, W.M. Wilcko and M.T. Wilcko. Selective alveolar decortication for rapid surgical-orthodontic resolution of skeletal malocclusion treatment. Distraction osteogenesis of the facial skeleton. (Italy, pmph usa, 2006) 199-203.

[7]. H. Nowzari, F.K. Yorita and H.C. Chang. Periodontally accelerated osteogenic orthodontics combined with autogenous bone grafting. Compend Contin Educ Dent, 29(4), 2008, 200-206.

[8]. P.S. Vig, J.A. Weintraub and C. Brown. The duration of orthodontic treatment with and without extractions: a pilot study of 5 selected practices. Am J Orthod Dentofacial Orthop, 97(1), 1990, 45-51.

[9]. I. Kocadereli. Changes in soft tissue profile after orthodontic treatment with and without extractions. Am J Orthod Dentofacial Orthop, 122(1), 2002, 67-72.

[10]. J. Duker. Experimental animal research into segmental alveolar movement after corticotomy. J Maxillofacial Surg, 3(2), 1975, 8184.

[11]. W.M. Wilcko, M.T. Wilcko and J.E. Bouquot. Rapid orthodontics with alveolar reshaping: two case reports of decrowding. Int J Periodontics Restorative Dent, 21(1), 2001, 9-19.

[12]. H.M. Frost. The regional acceleratory phenomenon: a review. Henry Ford Hosp Med J, 31(1), 1983, 3-9.

[13]. J.D. Sebaoun, A. Kantarci, J.W. Turner and R.S. Carvalho, T.E. Van Dyke, D.J. Ferguson. Modeling of trabecular bone and lamina dura following selective alveolar decortication in rats. J Periodontol 79(9), 2008, 1679-1688

[14]. M.S. Shih and R.W. Norrdin. Regional acceleration of remodeling during healing of bone defects in beagles of various ages. Bone, 6(5), 1985, 377-379.

[15]. M.T. Wilcko, W.M. Wilcko, J.J. Pulver, N.F. Bissada and J.E. Bouquot. Accelerated osteogenic orthodontics technique: A 1-stage surgically facilitated rapid orthodontic technique ith alveolar augmentation. J Oral Maxillofac Surg, 67(10), 2009, 2149-2159.

[16]. G. Amit, J.P.S. Kalra, B. Pankaj, S. Suchinder and B. Parul. Periodontally accelerated osteogenic orthodontics (PAOO)- a review. J Clin Exp Dent, 4(5), 2012, 292-296.

[17]. S. Dibart, J.D. Sebaoun and J. Surmenian. Piezocision: aminimaly invasive, periodontally accelerated orthodontic tooth movement procedure. Compend Contin Educ Dent, 30(6), 2009, 342-344, 346, 348-50.

[18]. K.G. Murphy, M.T. Wilcko, W.M. Wilcko and D.J. Ferguson. Periodontally accelerated osteogenic orthodontics: a description of the surgical technique. J Oral Maxillofac Surg, 67(10), 2009, 2160-2166.

[19]. A.S.T. AlGhamdi. Corticotomy facilitated orthodontics: Review of the technique. The Saudi Dental Journal, 22(1), 2010, 1-5.

[20]. H. Yu, F. Jiao, B. Wang, S.G.Shen. Piezoelectric decortication applied in periodontally accelerated osteogenic orthodontics. $J$ Craniofac Surg, 24(5), 2013, 1750-1752. 